\title{
UTILITY OF EXTENDED FOCUSED ASSESSMENT WITH SONOGRAPHY IN BLUNT CHEST TRAUMA- ITS CLINICAL IMPLICATION AND ITS SENSITIVITY COMPARED WITH CHEST X-RAY AND CLINICAL EXAMINATION
}

\author{
Chitra Subramaniam¹, D. Ashoka Chakaravarthy² \\ ${ }^{1}$ Associate Professor, Department of Surgery, Madurai Medical College. \\ ${ }^{2}$ Assistant Professor, Department of Surgery, Madurai Medical College.
}

\section{ABSTRACT}

\section{BACKGROUND}

Ultrasound study of thorax in a trauma patient is termed as Extended Focused Assessment with Sonography for Trauma (EFAST). Its diagnostic accuracy is not yet well-defined for its clinical implication.

The aim of the study is to check the accuracy of EFAST in diagnosing pneumothorax compared to chest x-ray and clinical examination in blunt injury chest patients keeping CT chest as standard investigation for confirmation.

\section{MATERIALS AND METHODS}

It was a prospective study, which included patients admitted in Govt. Rajaji Hospital Trauma Care Centre with blunt injury chest for a period of one year. In this study all blunt injury chest patients were subjected to clinical examination, chest x-ray, EFAST and their results were collected. CT chest was done for confirmation of pneumothorax. Finally, EFAST results were compared with chest x-ray and clinical findings.

\section{RESULTS}

Totally, 140 patients with blunt injury chest were evaluated. Among them 58 patients were diagnosed as having pneumothorax by CT. EFAST showed 42 positive cases of pneumothorax (sensitivity $=72.41 \%$ ), clinical examination showed 36 positive cases (sensitivity $=62.07 \%$ ), chest $\mathrm{x}$-ray diagnosed only 10 cases of pneumothorax (sensitivity $=17.24 \%$ ).

\section{CONCLUSION}

EFAST is an efficient modality of investigation that can be used to diagnose pneumothorax in trauma patients. It is cheap, available easily portable, not radiation associated, can be done along with resuscitation process and more sensitive than chest x-ray or clinical examination, in diagnosing pneumothorax makes it a suitable tool for surveying blunt chest trauma patients.

\section{KEYWORDS}

EFAST, Blunt Chest Trauma.

HOW TO CITE THIS ARTICLE: Subramaniam C, Chakaravarthy DA. Utility of extended focused assessment with sonography in blunt chest trauma - its clinical implication and its sensitivity compared with chest x-ray and clinical examination. J. Evolution Med. Dent. Sci. 2017;6(4):328-333, DOI: $10.14260 /$ Jemds/2017/73

\begin{abstract}
BACKGROUND
Even though USG was used as an important diagnostic tool in 1970 's, its role in trauma got its lime light in 1996 when Rozycki et al introduced FAST (Focused Assessment with Sonography for Trauma).[1,2] Its use was recognised and accepted as a secondary tool in ATLS (Advanced Trauma Life Support) since 1997.[3]

The main advantage in doing an ultrasonography as a diagnostic tool in trauma is that it can be shifted to bedside and can be done by a surgeon/radiologist during resuscitation process. It is cost effective and can be available in even small centres. $[4,5,6,7]$
\end{abstract}

Financial or Other, Competing Interest: None.

Submission 04-12-2016, Peer Review 01-01-2017,

Acceptance 06-01-2017, Published 12-01-2017.

Corresponding Author:

Dr. Chitra Subramaniam,

Associate Professor,

Department of Surgery,

Madurai Medical College,

Government Rajaji Hospital,

Madurai-625020,

Tamilnadu.

E-mail: chitra.madurai@gmail.com

DOI: $10.14260 /$ jemds $/ 2017 / 73$
Since road traffic accidents were on the rise, blunt injury chest and incidence of pneumothorax ( $>20 \%$ in major blunt traumas) were also rising, more in the developing countries.[8] Pneumothorax is an acute emergency, where timely intervention is needed to prevent mortality.

Pneumothoraces often are detected by means of a combination of clinical examination and chest radiography. Although, these techniques are reliable for the detection of large pneumothoraces, a subtle pneumothorax may be difficult to detect in a trauma situation for several reasons.[9] Pneumothorax may not be clinically evident if it does not cause substantial respiratory compromise or if it causes only a subtle decrease in air entry, which may not be detectable at auscultation.[10,11,12]

Till now chest x-ray is being used as a primary modality of investigation in blunt injury chest to rule out haemopneumothorax in many centres, even though its sensitivity and specificity is questionable.[9] Problem with chest $\mathrm{x}$-ray includes shifting unstable patients to $\mathrm{x}$-ray rooms is not practically possible, positioning a suspected spine injury patients for x-ray, radiation hazard and finally its poor sensitivity in detecting pneumothorax.[9,13] CT chest is the gold standard investigation in detecting pneumothorax but its cost, availability, radiation hazard limits its use.[14] 
Use of ultrasound for chest injuries is a new modality of investigation in trauma, which is gaining its significance as it has no radiation hazard, can be done safely in pregnant women and children, cheap, available in most of the centres, can be shifted to bed side of the patient and can be done along with resuscitation process. ${ }^{[15,16,17]}$ This FAST (Focused Assessment with Sonography for Trauma) for chest injuries is termed as Extended Focused Assessment with Sonography for Trauma (EFAST).[18,19,20]

This study is intended to check the utility of EFAST in blunt chest trauma and its diagnostic accuracy in comparison with chest x-ray and clinical examination keeping CT chest as gold standard.

\section{MATERIALS AND METHODS}

\section{Design of Study}

Prospective study.

\section{Period of Study}

1 year (August 2015 to August 2016).

\section{Collaborating Department}

Radiology.

\section{Selection of Study Subjects}

All patients satisfying inclusion criteria admitted in Govt. Rajaji Hospital for a period of 1 year.

\section{Inclusion Criteria}

All blunt chest trauma patients admitted in Govt. Rajaji Trauma Care Centre who requires CT chest evaluation.

\section{Exclusion Criteria}

- Haemodynamically unstable patients.

- Pregnant mothers.

- Patients in whom chest tube was inserted before CT chest examination.

- Penetrating chest trauma.

\section{Data Collection}

- Data regarding ultrasonographic findings of pneumothorax.

- Clinical signs of pneumothorax.

- Chest x-ray findings of pneumothorax.

- Finally, compared with computed tomography chest findings of pneumothorax.

\section{Method of Study}

Study of comparison.

\section{Measurements and Data}

Patients with blunt injury chest after initial primary survey, thorough clinical examination of chest is done and looked for any reduced breath sounds, chest tenderness, crepitus (subcutaneous emphysema/fracture ribs), reduced tactile fremitus and increased resonance. Based on the results, pneumothorax was diagnosed. Then the patients were subjected to EFAST with the patient in a supine position and at the most superior portion of the chest, usually in the third or fourth intercostal space in the mid-clavicular line.
The ribs are identified. These will appear hyperechoic and their acoustic shadows will appear as hypoechoic rays extending from the ribs. The interspace between the 2 ribs is used as a fixed anatomic landmark during the examination. Next, the pleural line is identified. This is a hyperechoic line found at the inferior border of the space between the 2 ribs. Presence any one of the following findings were considered as positive for pneumothorax.

1. The absence of pleural (lung) sliding.

2. The absence of so-called comet-tail artifacts, also referred to as B-lines.

3. The absence of a lung pulse.

4. The presence of one or more lung points.

The so-called lung point is a somewhat recently described sign that although difficult to identify, is pathognomonic for a pneumothorax and can be used to measure the size of the pneumothorax.

EFAST is followed by chest x-ray PA view and CT chest. Chest CT is considered as diagnostic of pneumothorax and tube thoracostomy was based on clinical and CT findings. Statistical analysis of mechanism of injury, age/sex distribution, bilateral pneumothorax incidence, sensitivity of EFAST in diagnosing pneumothorax compared to chest $\mathrm{x}$-ray and clinical examination.

\section{RESULTS}

We conducted study on one hundred and forty patients who had a history of blunt chest trauma, admitted in Govt. Rajaji Hospital Trauma Care Centre, Madurai, for the period of one year.

\section{Age Distribution}

Most common age group falls under 31 to 40 years, next followed by 41-50 years. Extremes of ages were seems to be the minimal. This might be due to the fact that middle aged men were the once who uses the motor vehicles more often than others.

\section{Sex Distribution}

Among the 140 patients, 124 patients were male and only 16 patients were females.

\section{Mechanism of Injury}

The most common incidence of blunt injury chest comes under RTA (Road Traffic Accident), which accounts for $78.57 \%$ of the cases followed by AF (Accidental Fall), which accounts for $12.86 \%$.

\begin{tabular}{|c|c|c|}
\hline Mechanism of Trauma & No. of Cases & Percentage \\
\hline AF & 18 & 12.86 \\
\hline Assault & 3 & 2.14 \\
\hline FFH & 9 & 6.43 \\
\hline RTA & 110 & 78.57 \\
\hline Total & $\mathbf{1 4 0}$ & $\mathbf{1 0 0 . 0 0}$ \\
\hline \multicolumn{2}{|c|}{ Table 1 } \\
\hline
\end{tabular}




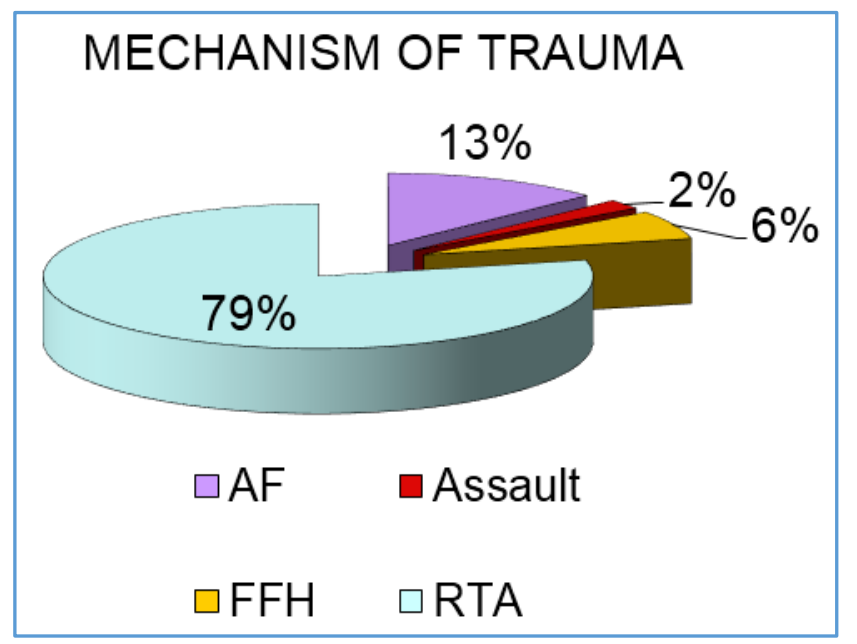

Out of 140 patients who were presented with blunt injury chest (only those who met the inclusion criteria of our study) were examined thoroughly and based on the clinical findings 36 patients were diagnosed of having pneumothorax.

All 140 patients were after initial treatment measures (except tube thoracostomy) were subjected to chest $\mathrm{x}$-ray, EFAST and CT chest one by one. CT findings were interpreted finally after all other investigations.

By chest x-ray of 140 patients, only 10 patients show positive findings for pneumothorax on ultrasound thorax on both hemithorax for all the patients showed positive pneumothorax signs in 42 patients.

After diagnosis of pneumothorax by all other means, CT chest results were obtained. Out of 140 patients under observation, 58 patients were found to have pneumothorax. Since CT chest is considered as a gold standard investigation, diagnosis of pneumothorax by all other means is compared with CT and sensitivity of each tests were predicted.

\begin{tabular}{|c|c|}
\hline Findings & No. of Cases \\
\hline CT Chest & 58 \\
\hline USG & 42 \\
\hline Clinical findings & 36 \\
\hline Chest X-ray & 10 \\
\hline Combined CF + CXR & 38 \\
\hline \multicolumn{2}{|c|}{ Table 2 } \\
\hline
\end{tabular}

\begin{tabular}{|c|c|}
\hline Findings & Sensitivity \% \\
\hline CT Chest & 100 \\
\hline USG & 72.41 \\
\hline Clinical findings & 62.07 \\
\hline Chest X-ray & 17.24 \\
\hline Combined CF + CXR & 65.5 \\
\hline \multicolumn{2}{|c|}{ Table 3 } \\
\hline
\end{tabular}

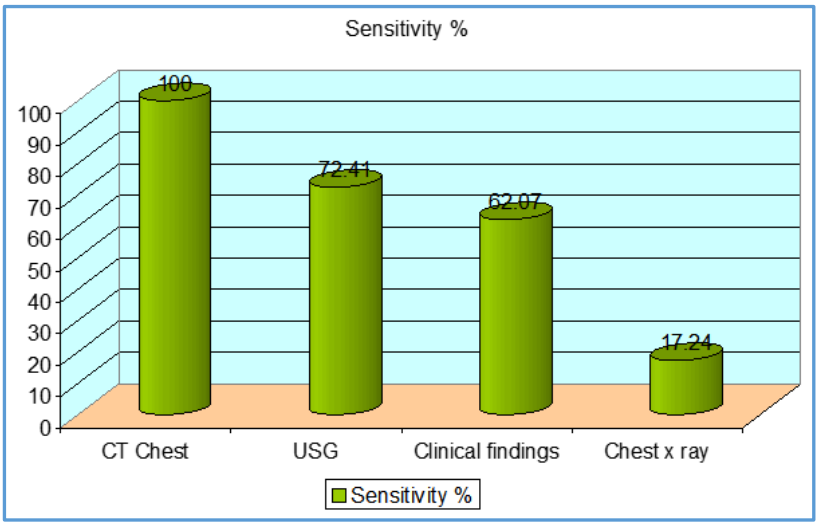

The sensitivity of chest x-ray seems to be the least with a sensitivity of only $17.24 \%$, USG has a very good sensitivity of $72.41 \%$. Sensitivity of EFAST, CXR, CF compared with the CT chest is given below -
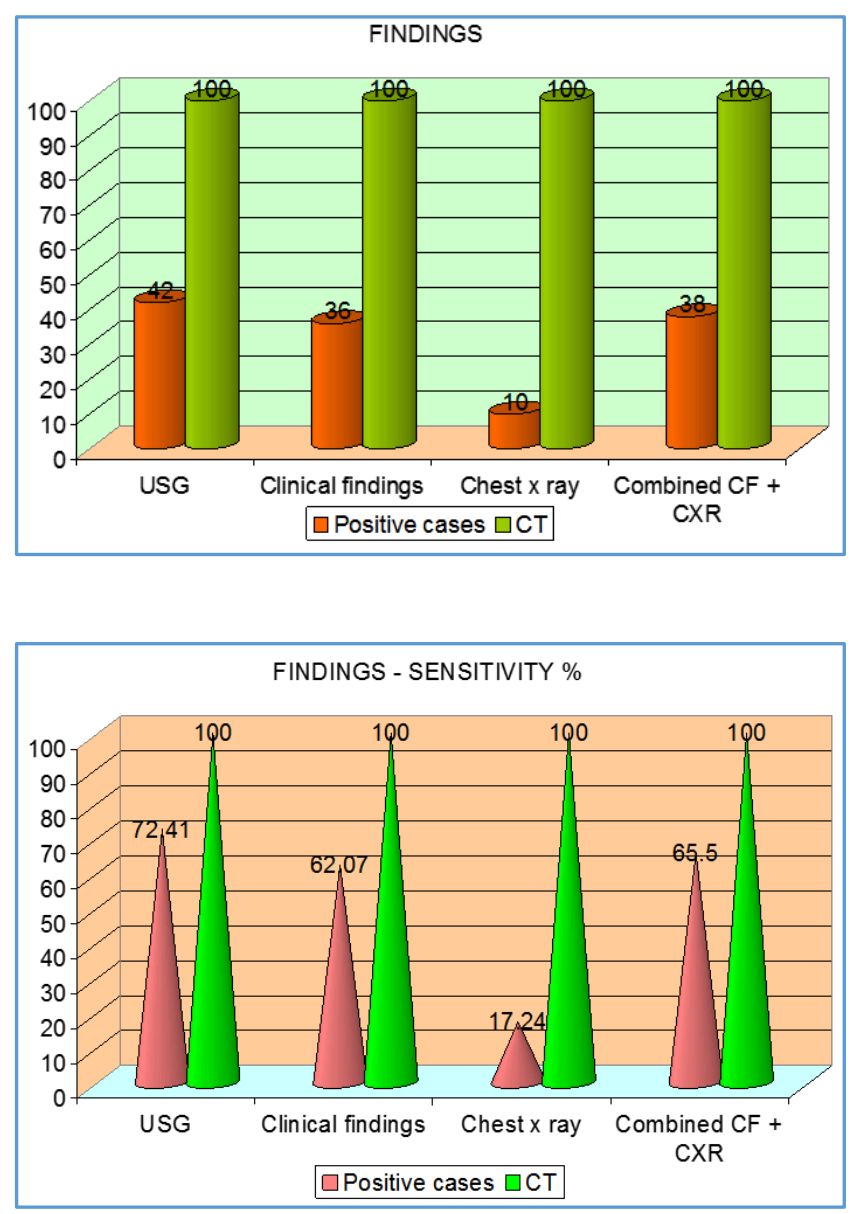

Comparison of USG thorax with clinical finding, chest x-ray and combined chest $x$-ray with clinical findings in diagnosis of pneumothorax is shown below -

\begin{tabular}{|c|c|}
\hline USG & 72.41 \\
\hline Chest x-ray & 17.24 \\
\hline \multicolumn{2}{|c|}{ Table 4 } \\
\hline
\end{tabular}




\begin{tabular}{|c|c|}
\hline USG (42) & 72.41 \\
\hline Combined CF + Chest x-ray (38) & 65.5 \\
\hline Table 5 & \\
\hline
\end{tabular}
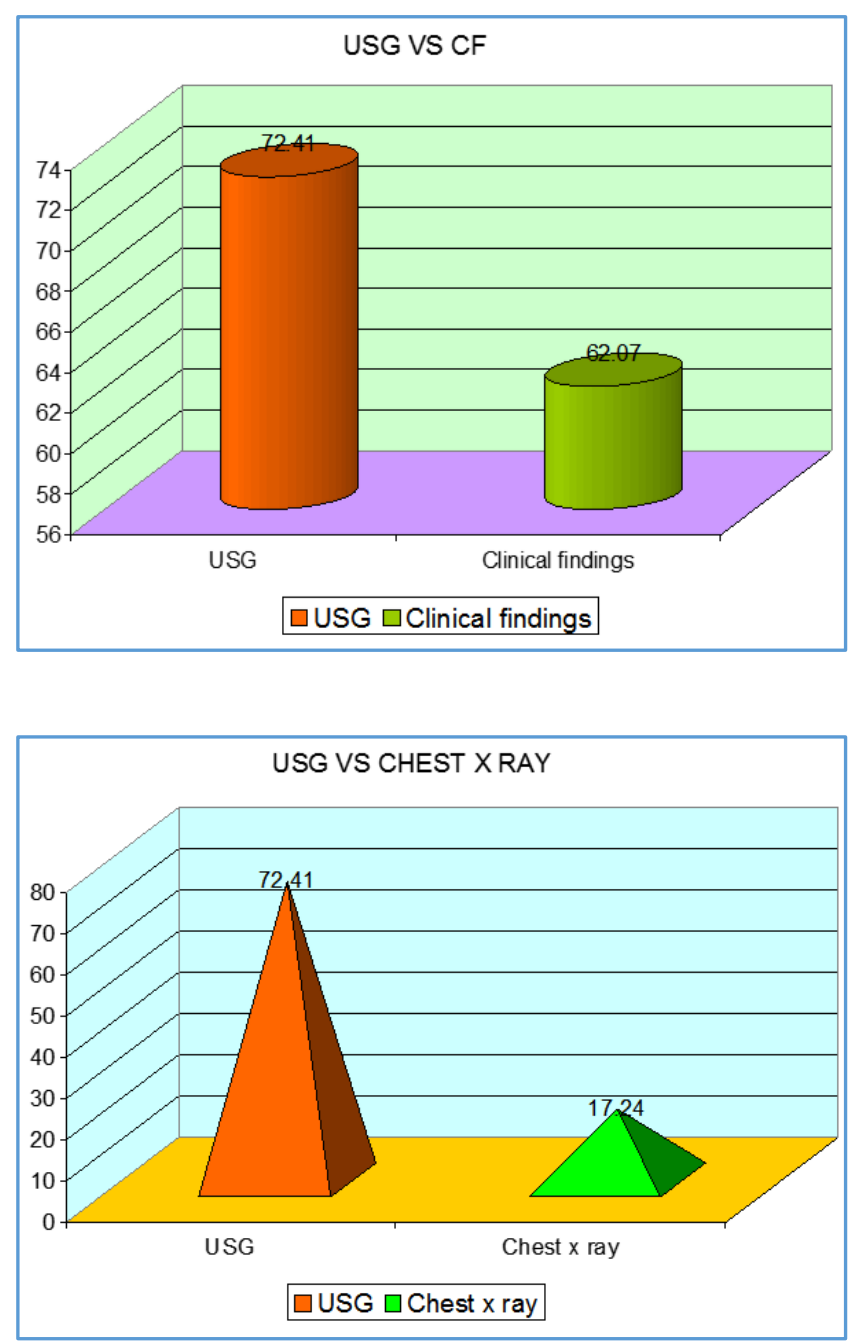

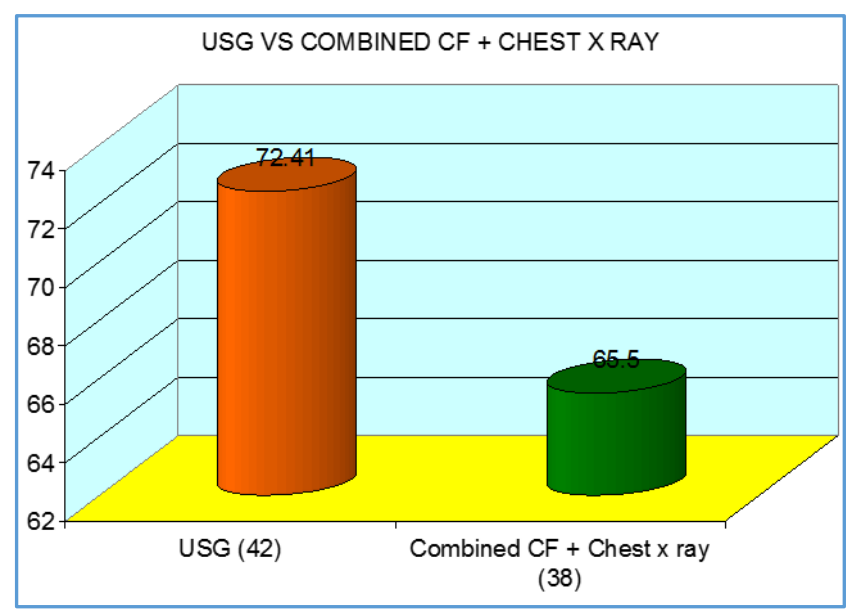

These observations clearly shows that USG thorax has greater performance than the combined modality of clinical diagnosis and chest $x$-ray.

The specificity of both ultrasound thorax and chest x-ray was found to be $100 \%$ in our study. No false positive cases were recorded in both the modalities.

Similarly, sensitivity and specificity of chest x-ray in diagnosis pneumothorax is given below -

\begin{tabular}{|c|c|c|}
\hline Pneumothorax/USG & True Positive & False Positive \\
\hline Yes & 42 & True negative \\
\hline & False negative & 82 \\
\hline No & 16 & \\
\hline Sensitivity & $72.41 \%$ & \\
\hline Specificity & $100.00 \%$ & \\
\hline \multicolumn{2}{|c|}{ Table 6 } \\
\hline
\end{tabular}

\begin{tabular}{|c|c|c|}
\hline Chest X-Ray & True Positive & False Positive \\
\hline Yes & 10 & True negative \\
\hline & False negative & 82 \\
\hline No & 48 & \\
\hline Sensitivity & $17.24 \%$ & \\
\hline Specificity & $100.00 \%$ & \\
\hline \multicolumn{2}{|r}{ Table 7 } \\
\hline
\end{tabular}

\section{Bilateral Incidence}

58 cases out of 140 blunt chest injury patients were considered as positive for pneumothorax (CT as confirmation). Among the 58 cases, number of bilateral cases were 16 . 


\begin{tabular}{|c|c|}
\hline Pneumothorax & 58 \\
\hline Unilateral & 42 \\
\hline Bilateral & 16 \\
\hline \multicolumn{2}{|c|}{ Table 8 } \\
\hline
\end{tabular}

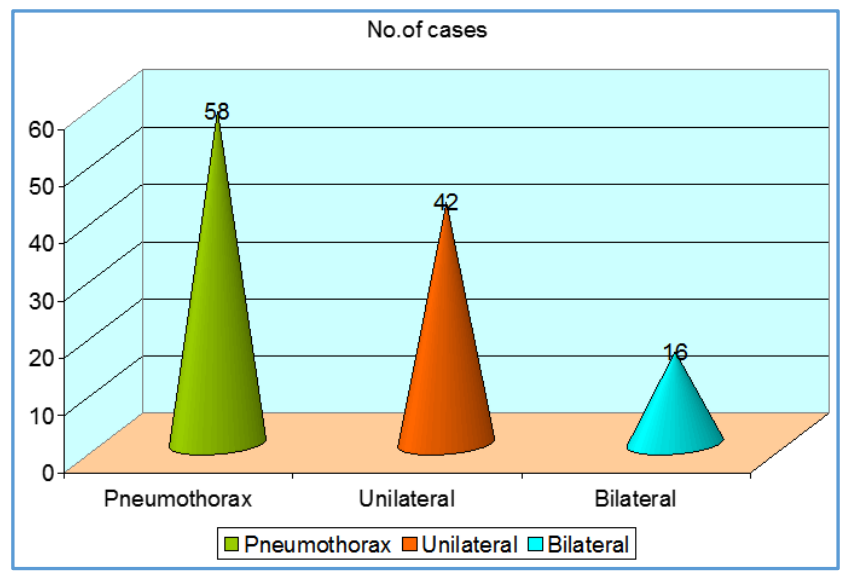

\section{CONCLUSION}

From the observation, we came to a conclusion that USG though highly specific for Pneumothorax (specificity 100\%), its sensitivity for detection of Pneumothorax is less (Sensitivity $72.4 \%$ ). X-ray chest though $100 \%$ specific for Pneumothorax its sensitivity is $17.2 \%$, which is very less. So USG is a better investigation for detection of Pneumothorax as its sensitivity is high and it can also detect intra-abdominal injuries if combined on EFAST. In view of -

- Availability in small centres,

- Cost,

- Radiation exposure,

- Portability of equipment to bedside,

- To evaluate haemodynamically unstable patients,

- And finally, specificity makes ultrasound chest to be the better investigation modality for blunt injury chest and can be combined with FAST as an "Extended FAST," which can prevent the morbidity and mortality due to difficulty in diagnosis of pneumothorax in time and prompt intervention.

\author{
Abbreviations \\ AF - Accidental Fall. \\ CT - Computed Tomography. \\ FFH - Fall from Height. \\ RTA - Road Traffic Accident. \\ EFAST - Extended Focused Assessment with \\ Sonography in Trauma. \\ USG - Ultrasonography. \\ CXR - Chest X-Ray.
}

\section{REFERENCES}

[1] Musthafa S, Hakim SY, Nabir S, et al. Utility of extended fast in blunt chest trauma: is it the time to be used in the ATLS algorithm. World J Surg 2015;39(1):172-8.

[2] Ascher WM, Parvin S, Virgilio RW, et al. Echographic evaluation of splenic injury after blunt trauma. Radiology 1976;118(2):411-5.
[3] Kristensen JK, Buemann B, Keuhl E. Ultrasonic scanning in the diagnosis of splenic haematomas. Acta Chir Scand 1971;137(7):653-7.

[4] Ball CG, Hameed SM, Evans D, et al. Occult pneumothorax in the mechanically ventilated trauma patient. Can J Surg 2003;46(5):373-9.

[5] Zhang M, Liu ZH, Yang JX, et al. Rapid detection of pneumothorax by ultrasonography in patients with multiple trauma. Crit Care 2006;10(4):R112.

[6] Wernecke K, Galanski M, Peters PE, et al. Pneumothorax: evaluation by ultrasound-preliminary results. J Thorac Imaging 1987;2(2):76-8.

[7] Dulchavsky SA, Schwarz KL, Kirkpatrick AW, et al. Prospective evaluation of thoracic ultrasound in the detection of pneumothorax. J Trauma 2001;50(2): 201-5.

[8] Rozycki GS, Ochsner MG, Schmidt JA, et al. A prospective study of surgeon-performed ultrasound as the primary adjuvant modality for injured patient assessment. J Trauma 1995;39(3):492-8.

[9] Rozycki GS, Shackford SR. Ultrasound, what every trauma surgeon should know. J Trauma 1996;40(1): $1-4$.

[10] Knudtson JL, Dort JM, Helmer SD, et al. Surgeonperformed ultrasound for pneumothorax in the trauma suite. J Trauma 2004;56(3):527-30.

[11] Kirkpatrick AW, Sirois M, Laupland KB, et al. Hand-held thoracic sonography for detecting post-traumatic pneumothoraces: the extended focused assessment with sonography for trauma (EFAST). J Trauma 2004;57(2):288-95.

[12] Soldati G, Testa A, Sher S, et al. Occult traumatic pneumothorax: diagnostic accuracy of lung ultrasonography in the emergency department. Chest 2008;133(1):204-11.

[13] American College of Surgeons. Advanced trauma life support (ATLS) student manual. 6th edn. Chicago, IL: American College of Surgeons 1997.

[14] Di Bartolomeo S, Sanson G, Nardi G, et al. A populationbased study on pneumothorax in severely traumatized patients. J Trauma 2001;51(4):677-82.

[15] Wilkerson RG, Stone MB. Sensitivity of bedside ultrasound and supine anteroposterior chest radiographs for the identification of pneumothorax after blunt trauma. Acad Emerg Med 2010;17(1):11-7.

[16] Ball CG, Kirkpatrick AW, Laupland KB, et al. Factors related to the failure of radiographic recognition of occult posttraumatic pneumothoraces. Am J Surg 2005;189(5):541-6.

[17] Omar HR, Abdelmalak H, Mangar D, et al. Occult pneumothorax, revisited. J Trauma Manag Outcomes 2010;4:12. 


\section{Jemds.com}

[18] Husain LF, Hagopian L, Wayman D, et al. Sonographic diagnosis of pneumothorax. J Emerg Trauma Shock 2012;5(1):76-81.

[19] de Moya MA, Seaver C, Spaniolas K, et al. Occult pneumothorax in trauma patients: development of an objective scoring system. J Trauma 2007;63(1):13-7.
Original Research Article

[20] Rhea JT, Novelline RA, Lawrason J, et al. The frequency and significance of thoracic injuries detected on abdominal CT scans of multiple trauma patients. J Trauma 1989;29(4):502-5. 